$$
\begin{aligned}
& \text { D7- 115441 } \\
& I-22056
\end{aligned}
$$

$\mathrm{Y}-12$
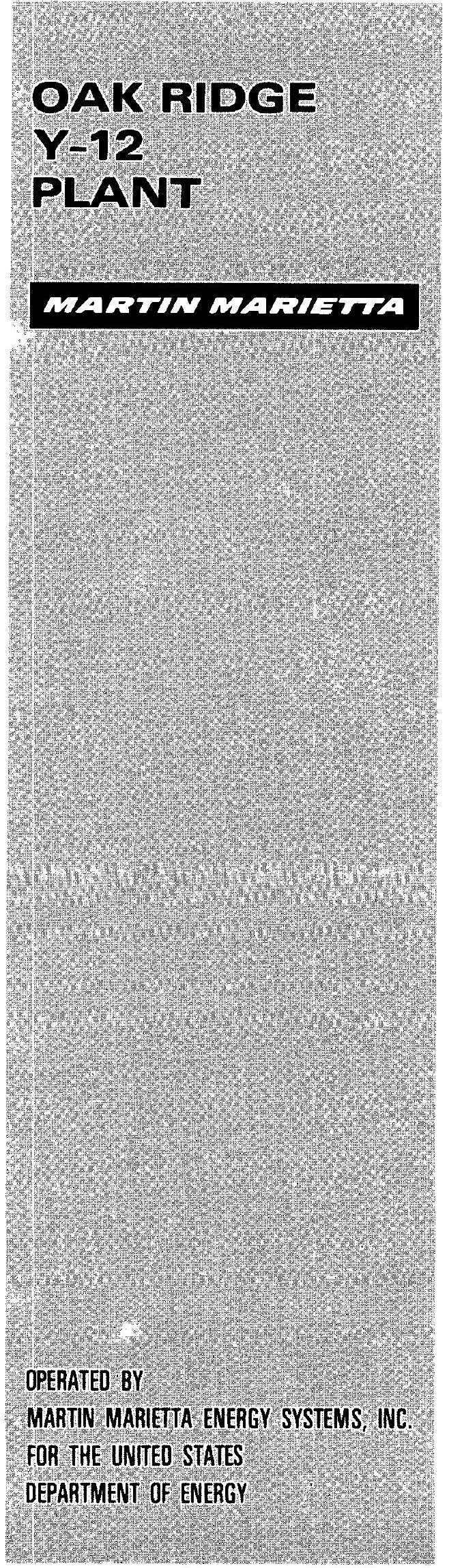

X-RAY DIFFRACTION STUDY OF REVERSIBLE DEFORMATION MECHANISMS IN THE AGED URANIUM-6.5 NIOBIUM ALLOY

D. A. Carpenter

June 1985

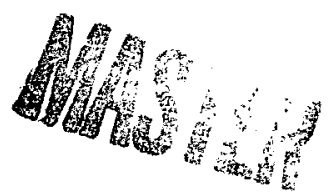




\section{DISCLAIMER}

This report was prepared as an account of work sponsored by an agency of the United States Government. Neither the United States Government nor any agency Thereof, nor any of their employees, makes any warranty, express or implied, or assumes any legal liability or responsibility for the accuracy, completeness, or usefulness of any information, apparatus, product, or process disclosed, or represents that its use would not infringe privately owned rights. Reference herein to any specific commercial product, process, or service by trade name, trademark, manufacturer, or otherwise does not necessarily constitute or imply its endorsement, recommendation, or favoring by the United States Government or any agency thereof. The views and opinions of authors expressed herein do not necessarily state or reflect those of the United States Government or any agency thereof. 


\section{DISCLAIMER}

Portions of this document may be illegible in electronic image products. Images are produced from the best available original document. 


\section{Printed in the United States of America. Available from National Technical Information Service \\ U.S. Department of Commerce \\ 5285 Port Royal Road, Springfield, Virginia 22161 \\ NTIS price codes-Printed Copy: A03 Microfiche A01}

\section{DISCLAIMER}

This report was prepared as an account of work sponsored by an agency of the United States Government. Neither the United States Government nor any agency thereof, nor any of their employees, makes any warranty, express or implied, or assumes any legal liability or responsibility for the accuracy, completeness, or usefulness of any information, apparatus, product, or process disclosed, or represents that its use would not infringe privately owned rights. Reference herein to any specific commercial product, process, or service by trade name, trademark, manufacturer, or otherwise, does not necessarily constitute or imply its endorsement, recommendation, or favoring by the United States Government or any agency thereof. The views and opinions of authors expressed herein do not necessarily state or reflect those of the United States Government or any agency thereof. 


\title{
X-RAY DIFFRACTION STUDY OF REVERSIBLE DEFORMATION MECHANISMS IN THE AGED URANIUM-6.5 NIOBIUM ALLOY
}

\author{
D. A. Carpenter \\ Instrumentation and Characterization Department \\ Y-12 Development Division
}

*Work performed prior to April 1, 1984, by Union Carbide Corporation Nuclear Division for the U. S. Department of Energy under contract W-7405-eng-26.

Oak Ridge $\mathbf{Y - 1 2}$ Plant

P. 0. BoX Y, Oak Ridge, Tennessee 37831

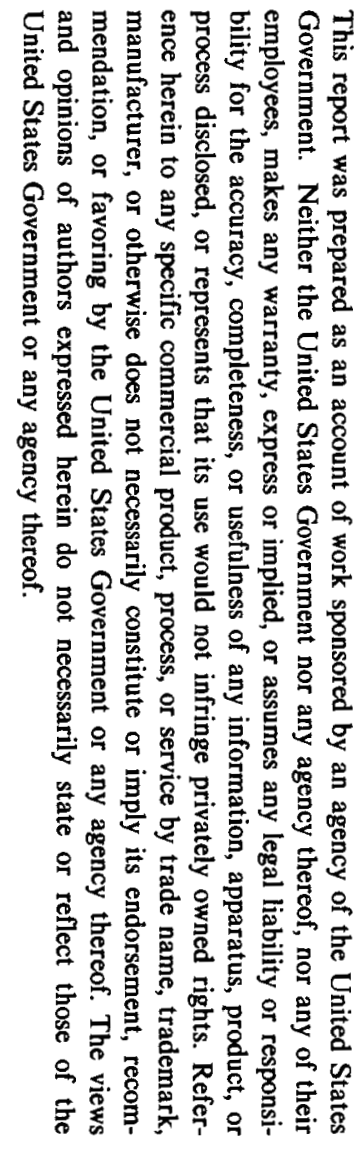

Prepared for the U.S. Department of Energy under Contract No. DE-AC05 840R21400

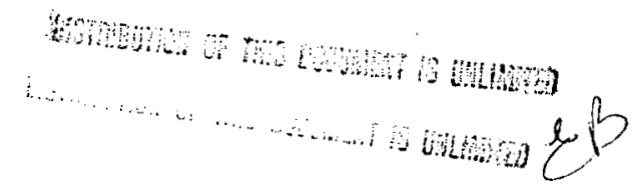




\begin{abstract}
The X-ray diffraction (XRD) data from $200^{\circ} \mathrm{C} / 2 \mathrm{~h}$-aged uranium-6.5 wt $\%$ niobium (U-6.5Nb) alloys, taken under stress as a function of strain, revealed a gamma-zero $\left(\gamma^{0}\right) \rightarrow$ alpha prime-prime $\left(\alpha^{\prime \prime}\right)$ thermoelastic martensitic phase transformation. It was concluded that the primary reversible deformation modes consisted of the movement of $\gamma \% / \alpha^{\prime \prime}$ interphase interfaces and $\alpha^{\prime \prime}$ intervariant interfaces. Specimen elasticity at low strains was associated with the retreat of interphase interfaces. At higher strains, interphase interfaces did not recover significantly on unloading, and elasticity was due primarily to the retreat of $\alpha^{\prime \prime}$ intervariant interfaces.
\end{abstract}


CONTENTS

SUMMARY . . . . . . . . . . . . . . . . . . . . . . . 4 INTRODUCTION . . . . . . . . . . . . . . . . . 5

X-RAY DIFFRACTION STUDY OF REVERSIBLE DEFORMATION MECHANISMS IN THE AGED URANIUM-6.5 NIOBIUM ALLOY . . . . 6

Literature Survey. . . . . . . . . . . . . . . . . 6

Experimental Procedure . . . . . . . . . . . . . . . . 7

Results . . . . . . . . . . . . . . . . . . . . 8

Discussion . . . . . . . . . . . . . . . . . . 14

Conclusions . . . . . . . . . . . . . . . . . . . . . . . 19

ACKNOWLEDGMENTS . . . . . . . . . . . . . . 20

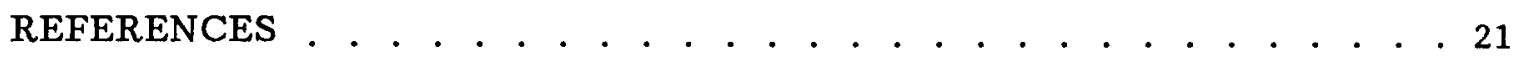




\section{SUMMARY}

The X-ray diffraction (XRD) data from $200^{\circ} \mathrm{C} / 2 \mathrm{~h}$-aged uranium-6.5 wt $\%$ niobium (U-6.5Nb) alloys, taken under stress as a function of strain, revealed a gamma-zero $\left(\gamma^{\circ}\right) \rightarrow$ alpha prime-prime $\left(\alpha^{\prime \prime}\right)$ thermoelastic martensitic phase transformation. The volume change accompanying the transformation increased from $1.29 \%$ at $0 \%$ strain to $6.8 \%$ at $3.75 \%$ strain. It was concluded that the primary reversible deformation modes consisted of the movement of $\gamma^{0} / \alpha^{\prime \prime}$ interphase interfaces and $\alpha^{\prime \prime}$ intervariant interfaces with a small contribution from a highly elastic, anisotropic lattice component. Specimen elasticity at low strains was associated with the retreat of interphase interfaces. At higher strains, interphase interfaces did not recover to a large extent, and elasticity was associated with the retreat of $\alpha^{\prime \prime}$ intervariant interfaces. The combination of the highly elastic lattice component with the retreat of interfaces may be responsible for the anelastic unloading response. 


\section{INTRODUCTION}

Increasing demands for greater dimensional stability in parts fabricated from uranium-6.0 wt $\%$ niobium (U-6.0Nb) have provided the impetus for studies of the causes of the unusual mechanical properties exhibited by this alloy. Recent studies have shown that the accommodation of large reversible strains, as well as the apparent low yield strength in water-quenched $U-6.0 \mathrm{Nb}$, was due to the movement of intervariant interfaces under stress. ${ }^{1-3}$ Because of the shape memory effect (SME), much of the reversible strain can be recovered by heating to temperatures just above room temperature. Thus, deformed material could be dimensionally unstable during fabrication.

For some applications, the material is used in the water-quenched and aged condition $\left(200^{\circ} \mathrm{C} / 2 \mathrm{~h}\right)$. The possibility existed that a stressinduced phase transformation involving a stabilized gamma-zero ( $\left.\gamma^{\circ}\right)$ phase could occur. An X-ray diffraction (XRD) study was initiated at the Oak Ridge $\mathrm{Y}-12$ Plant* to determine if such a transformation existed and, if so, to characterize it. A U-6.5Nb alloy was prepared whereby at room temperature it would contain both alpha prime-prime $\left(\alpha^{\prime \prime}\right)$ and ro phases. This alloy was chosen because a greater amount of the ro phase could be induced in it by aging than in the U-6.0Nb alloy, thereby facilitating the study of the transformation. Although all the work will be presented here, portions of this study have been published previously."

*Operated by Martin Marietta Energy Systems, Inc., for the U.S. Department of Energy. 


\section{X-RAY DIFERACTION STUDY OF REVERSIBLE DEFORMATION MECHANISMS IN THE AGED URANIUM-6.5 NIOBIUM ALLOY}

\section{LITERATURE SURVEY}

The alpha prime-prime $\left(\alpha^{\prime \prime}\right)$ and gamma-zero $\left(\gamma^{\circ}\right)$ metastable phases form when uranium-niobium alloys near the monotectoid composition are quenched from temperatures in the gamma-phase region. At room temperature, the $\alpha "$ phase was stable over the approximate range of 5.2 to 6.5 wt $\%$ niobium, while the $\gamma^{\circ}$ phase was stable over the approximate range of 6.9 to $7.8 \mathrm{wt} \%$ niobium. ${ }^{5,6}$ Both phases coexisted in the intermediate range. Dilatometry studies indicated that the formation of the $\alpha^{\prime \prime}$ phase was preceeded by the $\gamma^{\circ}$ phase. From that data, it was speculated that the $\gamma^{\circ}$ - to $\alpha^{\prime \prime}$-phase transformation was thermoelastic martensitic. ${ }^{\top}$

Thermoelastic martensitic transformations can be induced by both temperature and stress. As the temperature is decreased below the thermodynamic equilibrium temperature for transformation $\left(T_{0}\right)$, the freeenergy difference $(\Delta G)$ between the parent phase and the martensite phase increases, which tends to drive the transformation forward. Since the formation of martensite involves a discrete change in corresponding lattice distances of the parent phase, a back stress is generated which tends to oppose the forward transformation. In polycrystalline materials, additional sources of back stress arise from grain boundaries and lattice defects. This back stress can be overcome to some extent by further reducing the temperature and thereby increasing $\Delta G$. Another way to overcome the back stress is by mechanically deforming the sample. Stress-induced martensite (SIM) then forms in such a way as to accommodate the increasing strain. Twin variants of SIM, in which the resolved shear stress on the habit plane and in the shear direction is a maximum, are formed. This gives rise to a highly textured martensite.

Previous studies of the single crystals of alloys which transformed to thermoelastic martensites have shown that the transformation proceeded via a moving interface between parent and martensite. ${ }^{-10}$ The interfaces were apparently highly elastic. With $\mathrm{Cu}-\mathrm{Al}-\mathrm{Ni}$ alloys at temperatures well above the austenite-start temperature $\left(A_{S}\right)$, the transformation induced under stress was completely reversible on unloading. The stress-strain curves contained an initial elastic region, due to the need to reach a critical stress value for transformaton, followed by an easy-flow region corresponding to both forward and reverse transformations. The "superelasticity" exhibited by these alloys was apparently due to the elasticity of the interphase interfaces. On the other hand, when the temperature of deformation was reduced to just above the martensite-start temperature $\left(M_{S}\right)$, very little superelasticity occurred on unloading. However, on heating the unloaded sample above $A_{S}$, the strain was recovered. This shape memory effect (SME) occurred because the SIM variants transformed to parent grains with the same crystallographic orientations as those which existed before the deformation. Because of that transformation, the strain accommodation afforded by the oriented SIM variants vanished and the specimen returned to its original shape. 
Aging the $\alpha^{\prime \prime}$ uranium-niobium alloys near the monotectoid composition at temperatures near the $M_{s}$ temperature altered the transformation behavior and stabilized the $\gamma^{\circ}$ phase. ${ }^{11,12}$ Studies have shown that as a result of aging for short times below $300^{\circ} \mathrm{C}$, the alloys maintained good corrosion resistance while the yield strength and ductility increased. ${ }^{13}$ Aging for longer periods of time increased the yield strength but decreased the ductility. The stress-strain curve of the aged alloy was similar in shape to that of the water-quenched alloy, but shifted to higher stress levels. ${ }^{12}$ Both curves were characterized by a double plateau; the first plateau corresponding to reversible modes and the second to irreversible modes.

When the $\alpha^{\prime \prime}$ phase was aged at temperatures high in the ro region or in the gamma region, rapid isothermal changes occurred. ${ }^{14}$ Aging of U-6Nb alloy initially converted the $\alpha^{\prime \prime}$ phase to the $\gamma^{0}$ phase. Continued aging raised the $M_{s}$ temperature and converted the $\gamma^{0}$ phase to an isothermal $\alpha$ " phase--apparently by diffusion and subsequent segregation of niobium.

\section{EXPERIMENTAL PROCEDURE}

Ingots containing nominal $6.5 \mathrm{wt} \%$ niobium were prepared by a vacuum arc-melting procedure and then hot cross-rolled into 9.4-mm-thick plate. Flat tensile specimens with a gage thickness of $0.635 \mathrm{~mm}$ were cut from the center of the plate after it had been solution heat-treated for $7200 \mathrm{~s}$ at $1075 \mathrm{~K}$, aged at $475 \mathrm{~K}$ for $14 \mathrm{ks}$, then water-quenched. Samples 1 and 2, prepared in this manner, contained almost all $\gamma^{0}$ with a detectable amount of $\alpha^{\prime \prime}$. Sample 3, containing almost equal proportions of the two phases, was prepared by resolutioning a machined, water-quenched specimen, followed by water quenching and aging as above. Prior to XRD analysis, each sample was electropolished in a solution of phosphoric acid and chromic oxide. Approximately 100 to $150 \mu \mathrm{m}$ were removed from both sides of the specimens in two separate steps. Chemical analyses of samples cut from the centers of the gage lengths yielded 6.55, 6.50, and 6.47 wt $\%$ niobium for Samples 1, 2, and 3, respectively. Each sample contained traces of iron and silicon in addition to approximately 125 ppm carbon.

The specimens were positioned in a specially designed tensile jig that was mounted on an automated horizontal X-ray diffractometer. ${ }^{15}$ A hand-cranked screw mechanism mounted on the jig was used to load the specimens in tension. The stress axis was parallel to the horizontal plane and perpendicular to the diffraction vector. An extensometer was used to determine strain by measuring the change in distance between the two scribe marks placed 1 in. apart about the center of the gage length. A nickel-powder standard, calibrated against the National Bureau of Standards SRM 640 silicon standard, was used as a $2 \theta$ standard. The $\mathrm{X}$-ray data were collected using copper $\mathrm{K \alpha}$ radiation and a diffractedbeam graphite monochromator with standard counting electronics. The XRD patterns were measured in the unstressed condition and at small strain increments while the samples were under stress until fracture. Occasionally, at intermediate strain levels, patterns were measured after the specimens were unloaded, and then again while they were incrementally reloaded. 
Samples 1 and 2 were step-scanned in increments of $0.02^{\circ}$ in $2 \theta$ and a 4-s counting time. Because of the complexity of the diffraction pattern, an automated, segmented step-scan procedure was used for Sample 3 . In an effort to obtain good counting statistics, broad, weak peaks and highly overlapped peak groupings were step-scanned using relatively long counting times compared with regions of the pattern containing stronger and sharper peaks. Regions containing no peaks were skipped. Counting times and scan segments were selected by the operator before the first scan and stored in a file to be recalled for each successive increment. Peak profiles were fit with the squared Lorentzian function on a PDP $11 / 70$ computer using the Marquardt algorithm in an interactive mode. ${ }^{16}$ Lattice parameters were calculated using a least-squares routine. ${ }^{17}$

The $\alpha^{\prime \prime}$ volume fraction $\left(\nu_{\alpha} \prime\right)$ was calculated using the direct comparison method with calculated intensities as standards and using a combination of peaks whose average $I / R$ value (where $I$ is the experimental intensity and $R$ is the calculated intensity ${ }^{18}$ ) for each phase changed very little with changes in preferred orientation. ${ }^{19}$ These peaks were chosen by studying the strain response of the XRD patterns of single-phase $\alpha^{\prime \prime}$ and $\gamma^{\circ}$ alloys. ${ }^{1,20}$ The peaks used in the analysis are given in Table 1.

\begin{tabular}{|c|c|}
\hline$\alpha^{\prime \prime}$ phase & ro phase \\
\hline 020 & 111 \\
\hline 110 & 131 \\
\hline 110 & 022 \\
\hline 111 & \\
\hline 111 & \\
\hline 131 & \\
\hline
\end{tabular}

\section{RESULTS}

Figures 1, 2, and 3 show the XRD patterns of Samples 1, 2, and 3 in the as-received, maximum-strain, and final-unloaded conditions. Notice that Samples 1 and 2 contained large amounts of the $\gamma^{\circ}$ phase in the asreceived condition while Sample 3 contained almost a 1:1 ratio of $\alpha^{\prime \prime}$ to $\gamma^{\circ}$. The $\gamma^{\circ}$ phase transformed to the $\alpha^{\prime \prime}$ phase when each sample was deformed in tension.

Sample 1 was loaded to $1.8 \%$ strain, where the transformation to $\alpha^{\prime \prime}$ was only about $50 \%$ complete, and then unloaded. The sample strain was reduced to $0.3 \%$ after unloading, and the structure reverted back almost completely to $\gamma^{\circ}$. The interphase interfaces were apparently highly 


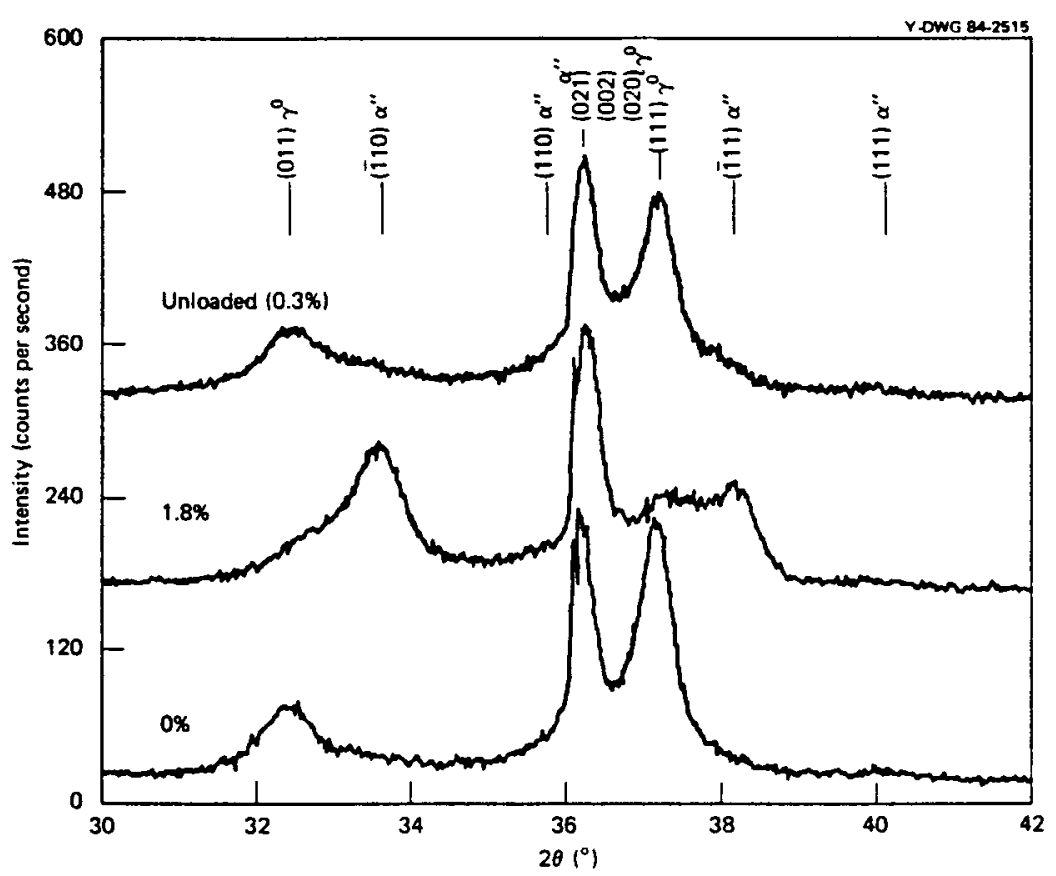

Fig. 1. The XRD patterns of aged U-6.55Nb (Sample 1) in the as-received, deformed, and unloaded conditions.

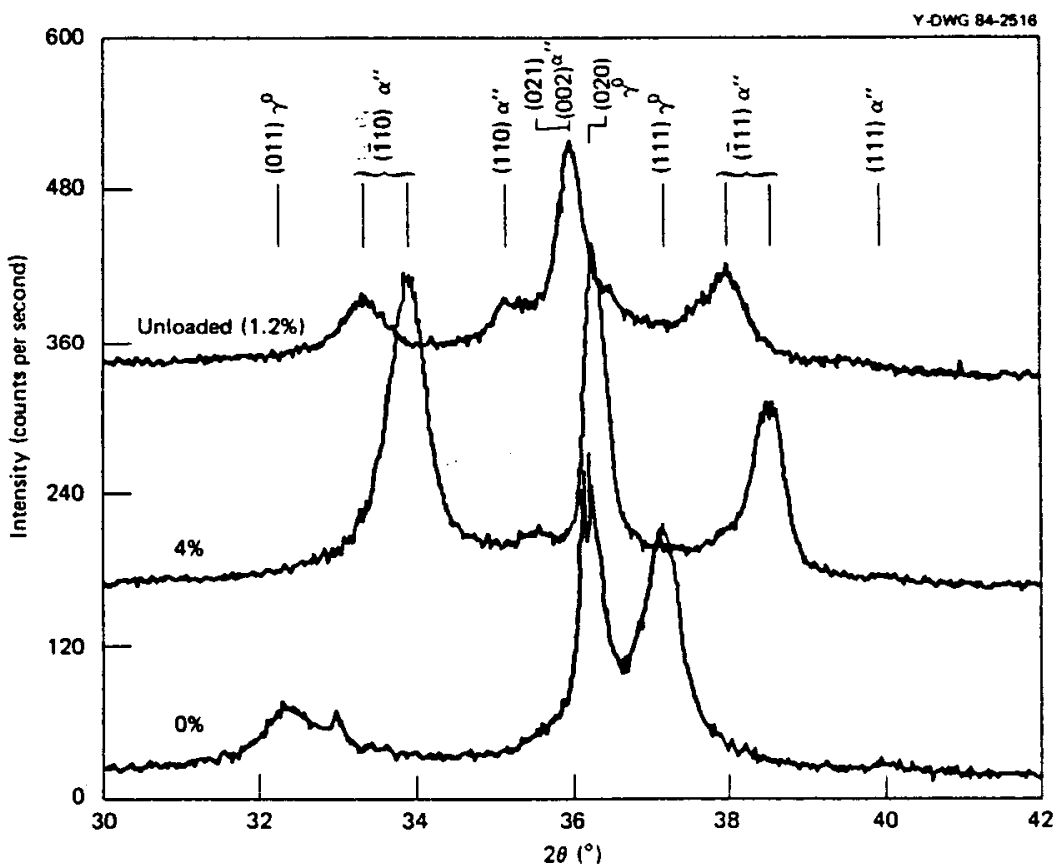

Fig. 2. The XRD patterns of aged U-6.50Nb (Sample 2) in the as-received, deformed and unloaded conditions. (The unloaded XRD pattern is shifted to lower $2 \theta$ values because of specimen misalignment. The central peak at $\sim 36^{\circ}$ should remain unshifted.) 


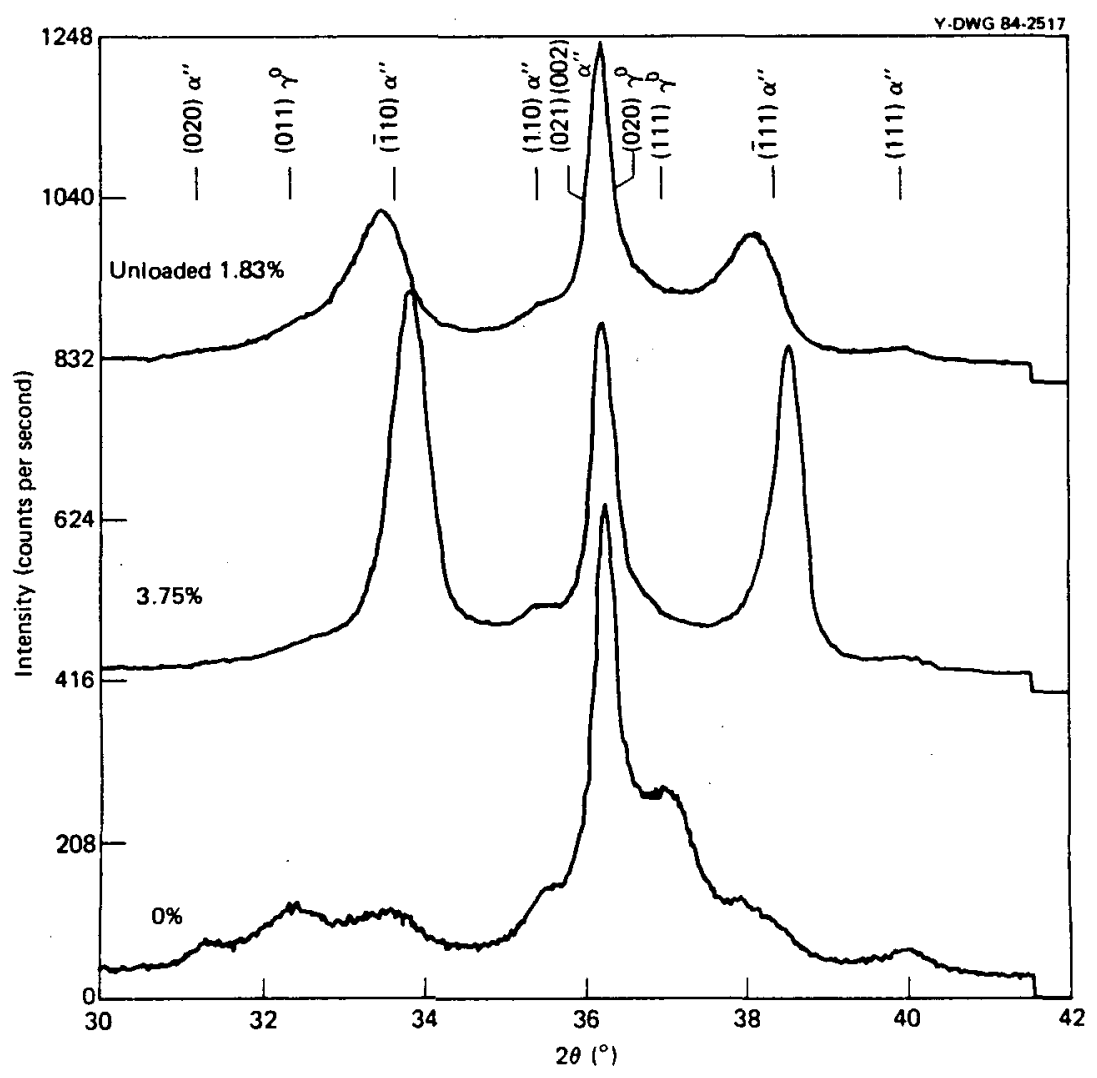

Fig. 3. The XRD patterns of $U-6.47 \mathrm{Nb}$ (Sample 3) in the as-received, deformed, and unloaded conditions.

elastic in this case. Sample 2 was loaded to $4 \%$ strain where only a highly textured $\alpha^{\prime \prime}$ XRD pattern was recorded; no $\gamma^{\circ}$ phase was detected. The $\alpha^{\prime \prime}$ texture was similar to that found in single-phase $\alpha^{\prime \prime}$ alloys deformed in tension ${ }^{1}$ and represented the formation of favorably oriented $\alpha^{\prime \prime}$ variants. When Sample 2 was unloaded, the strain was reduced to $1.2 \%$; however, the pattern consisted of essentially all $\alpha^{\prime \prime}-$-very little $\gamma$ o was observed. In addition, the $\alpha$ " was only weakly textured.

Attempts to make quantitative XRD measurements of the phase content, texture, and lattice parameters were hampered by broad, extensively overlapped peaks. These problems were alleviated to a large extent by the use of the segmented step-scan procedure. The technique was used with Sample 3 and gave reasonably good measurements of the peak parameters of both phases. Quantitative measurements of the volume fraction of the $\alpha$ " phase from the data from Sample 3 are shown in Figs $4 \& 5$. Shown also are changes in the average $I / R$ values for the XRD peaks used in the $v_{\alpha}$ " calculation and taken from single-phase $\alpha^{\prime \prime}$ and $\gamma^{\circ}$ alloys. The fact that these average $I / R$ values do not change with strain was a good indication that texture had little effect upon the $v_{\alpha}$ " calculations. 


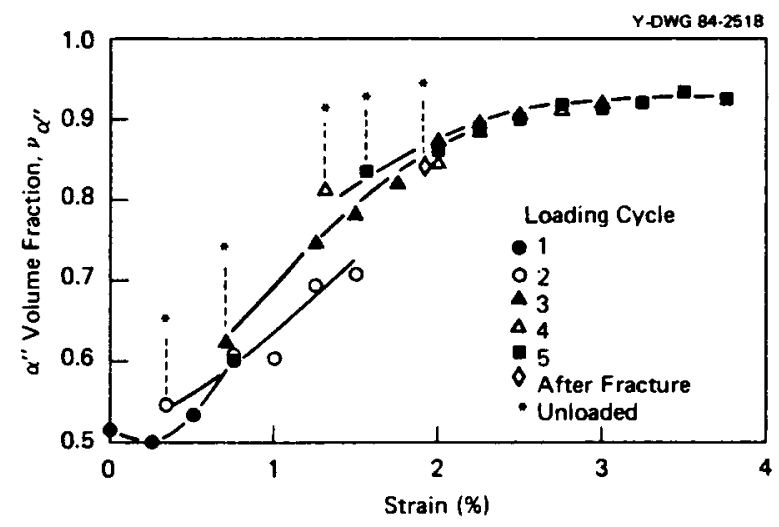

Fig. 4. Variation of the $\alpha^{n}$ volume fraction $\left(v_{\alpha}{ }^{n}\right)$ with strain for aged $U-6.47 \mathrm{Nb}$ alloy.

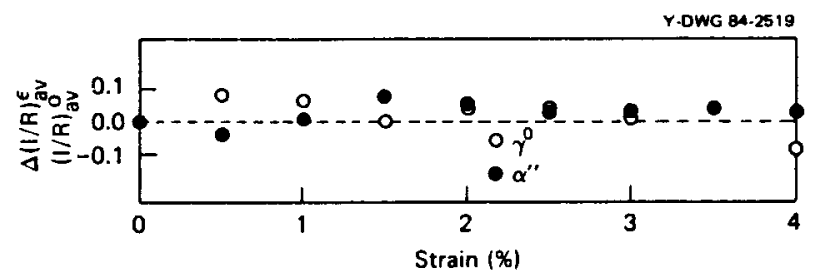

Fig. 5. Variation with strain of the average $I / R$ value of the peaks used for the calculation of $v_{\alpha} n$ in single-phase $\alpha^{n}$ and $\gamma^{\circ}$ alloys.

The first $0.5 \%$ strain apparently corresponded to the stress required for transformation to begin since no change in $v_{\alpha}$ " occurred. After $0.5 \%$ strain, an approximately linear transformation region was observed up to about $1.5 \%$ strain, followed by a gradual decrease in slope to an asymptotic $v_{\alpha}$ " value of about 0.93 .

The effects of midtest unloading on the $v_{\alpha}$ " are shown by the unloaded values marked by the asterisks. The figure an be interpreted in the following way. The first loading cycle, represented by the closed circles, extended to $0.75 \%$ strain and then the sample was unloaded. The unloaded value was the first point of the second loading cycle, represented by the open circles, at about $0.4 \%$ strain. The other unloaded points can be interpreted in a similar manner. The strain regions associated with the five strain cycles are given in Table 2. 
Table 2. Strain Regions associated with loading cycles for Sample 3

\begin{tabular}{ll}
\hline Cycle & \multicolumn{1}{c}{ Strain region (\%) } \\
\hline 1 & $0-0.75$ \\
2 & $0.34-1.50$ \\
3 & $0.70-2.25$ \\
4 & $1.26-3.00$ \\
5 & $1.56-3.75$ \\
& 1.83 (final unloaded strain)
\end{tabular}

The texture of the $\alpha^{\prime \prime}$ phase was separated from the effects of increasing $\nu_{\alpha}$ " by using the following expression:

$\mathrm{p}(\mathrm{hkl})=\left\{[\mathrm{I}(\mathrm{hkl}) / \mathrm{R}(\mathrm{hkl})]^{\epsilon} /[\mathrm{I} / \mathrm{R}]_{\mathrm{av}}{ }^{\epsilon}\right\} /\left\{[\mathrm{I}(\mathrm{hkl}) / \mathrm{R}(\mathrm{hkl})]^{\epsilon=0} /[\mathrm{I} / \mathrm{R}]_{\mathrm{av}}{ }^{\epsilon=0}\right\}$,

where,

$p(h k l)=$ texture factor for the (hkl) reflection,

$\mathrm{I}(\mathrm{hkl})=$ intensity of the (hkl) reflection,

$\mathrm{R}(\mathrm{hkl})=\mathrm{LP}-$ and temperature-corrected, squared structure factor,

$[I / R]$ ave $=$ average $I / R$ value for all $\alpha^{\prime \prime}$ reflections used in the $v_{\alpha} "$ calculations.

The results of the calculation are given in Fig. 6, where $p(h k l)$ for the $\alpha^{\prime \prime}$ phase (110) and (110) reflections are shown as a function of strain for Sample 3. Unloaded values are again indicated by asterisks. The increasing intensity of the (110) reflection and the decreasing intensity of the (110) reflection with increasing strain was similar to the pattern observed in the single-phase $\alpha^{\prime \prime}$ alloys subjected to increasing tensile deformation. ${ }^{1-3}$

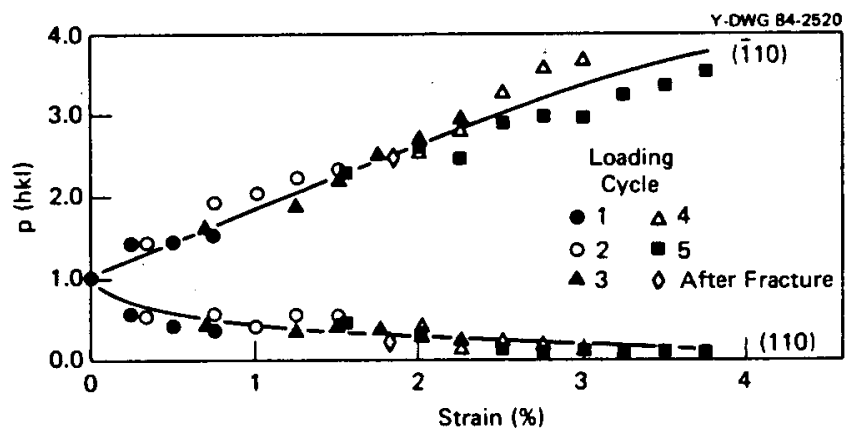

Fig. 6. The texture functions $p(\overline{1} 10)$ and $p(110)$ as a function of strain for a $\mathrm{U}-6.47 \mathrm{Nb}$ alloy (Sample 3). 
The changes in $v_{\alpha}$ " represented the movement of interphase interfaces in the transformation from ro to $\alpha^{\prime \prime}$. The formation of favored $\alpha^{\prime \prime}$ variants, as well as the texturing (movement of intervariant interfaces) of preexisting $\alpha^{\prime \prime}$, was indicated by the intensity changes occurring in the $\alpha^{\prime \prime}$ XRD pattern with increasing strain. It was of interest to examine the behavior of $v_{\alpha} "$ and $p(\overline{1} 10)$, as well as the lattice parameters of the two phases during each of the five strain cycles. Figure 7 shows a series of bar graphs depicting the changes in these parameters and comparing them with the corresponding changes in sample strain.
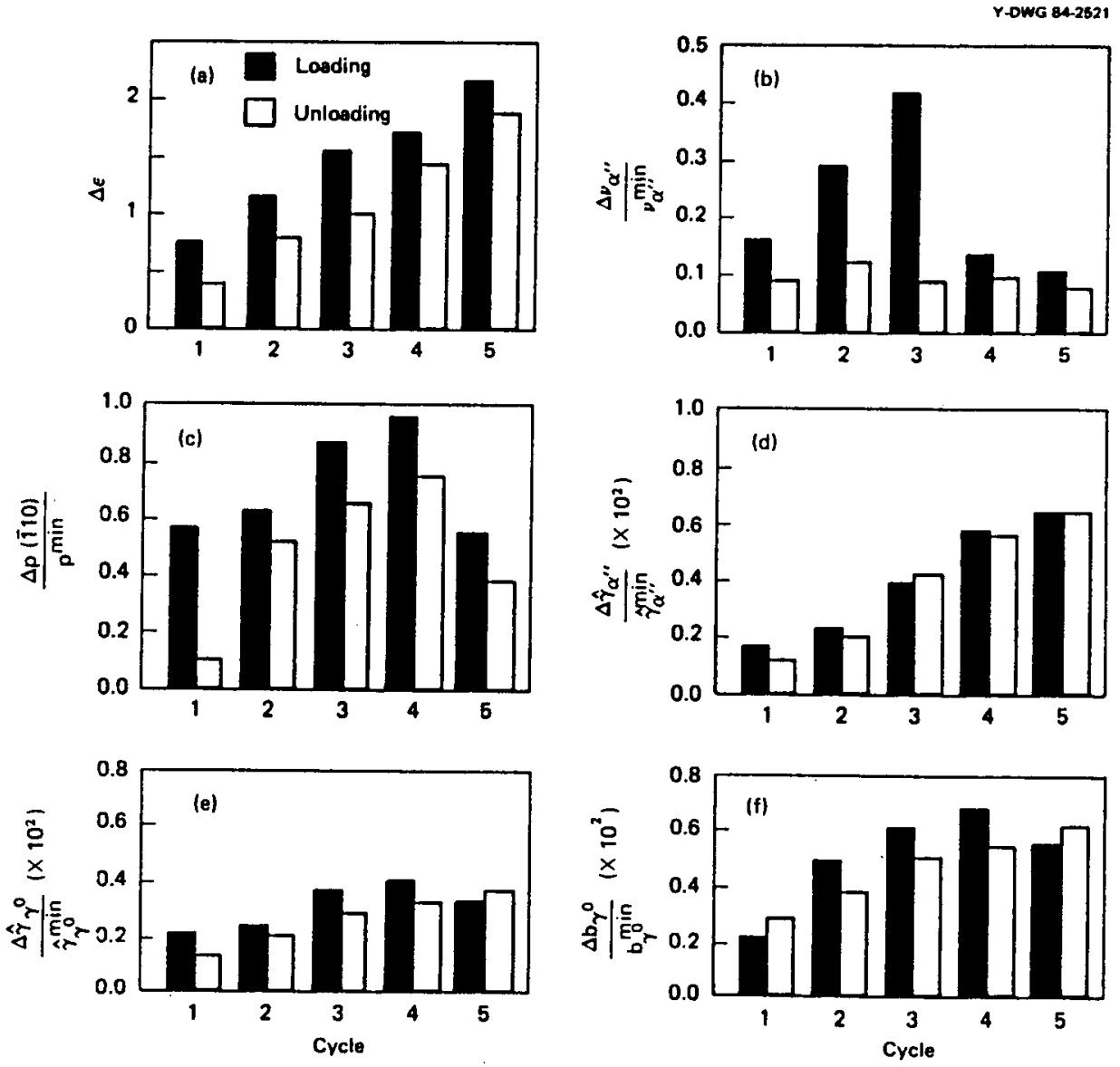

(a) Specimen strain.

(b) "a", representing movement of

(d) $\alpha^{\prime \prime}$-phase $\hat{\gamma}$ angle.

(e) $\boldsymbol{\gamma}^{0}$-phase $\hat{\gamma}$ angle.

(c) $p(\overline{1} 10)$, represented movement of

(f) $\gamma^{0}$-phase monoclinic b parameter. intervariant interfaces.

Figure 7. Changes in strain parameters during the five loading cycles.

During the first cycle, the change in $v_{\alpha}$ " was small and thus little movement of interphase interfaces occurred. This corresponded to the attainment of the critical stress for transformation and to the initial quasi-elastic region of the stress-strain curve. Apparently, there was movement of intervariant interfaces in the preexisting $\alpha^{\prime \prime}$ phase (and presumably the preexisting $\gamma^{0}$ phase) since significant intensity changes occurred, as indicated by the changes in $\mathrm{p}(\overline{1} 10)$. 
The large changes which occurred in $v_{\alpha}^{\prime \prime}$ during cycles 2 and 3 corresponded to the easy-flow region of the stress-strain curve caused by the movement of interphase interfaces. Notice that $p(\overline{110})$ also increased by a large amount during the second and third cycles. Much of the increase in $p(110)$ probably corresponded to the formation of the new oriented $\alpha^{\prime \prime}$ phase as a result of interphase interface movement; although, in the XRD data, it was not possible to distinguish between this process and texturing due to movement of the intervariant interfaces in the preexisting $\alpha^{\prime \prime}$. The fact that only one easy-flow region has been observed in the stress-strain curves of the aged alloys indicates that these two interface-moving processes are energetically similar.

One significant difference between the movement of interphase interfaces and intervariant interfaces can be seen in the extent of recovery of $\mathrm{p}(\overline{110})$ and $\nu_{\alpha}$ " on unloading during the second and third cycles. After significant transformation had occurred, the interphase interfaces showed little recovery compared with that of the intervariant interfaces (presumably associated with both new and old $\alpha^{\prime \prime}$ ). This was consistent with the observations of Sample 2 (Fig. 2) discussed previously.

The loading and recovery strains associated with cycles 4 and 5 were larger than the other cycles. Yet, the interphase interface movement was relatively small while the intervariant interface movement was large. This was a consequence of the low recovery of interphase interfaces during the previous cycle compared with the recovery of the intervariant interfaces. The data show that after the phase transformation was essentially complete, strain accommodation was associated primarily with the movement of highly elastic intervariant interfaces.

The lattice parameters of the two phases are given in Figs. 8, 9, and 10. The tetragonal lattice parameters were converted to the corresponding monoclinic parameters using the lattice correspondence between the $\alpha$-like and $\gamma$-like lattices. ${ }^{1,21}$ There were discrete differences between the $a, b$, and $\hat{\underline{\gamma}}$ parameters of the two phases. These differences were maintained over the entire transformation-strain region. In addition, the $\hat{\gamma}$ angle of the two phases (Fig. 9), as well as the ro-b parameter (Fig. 10), displayed unusual behavior during the transformation. All three parameters decreased sharply with increasing strain, but then they showed extensive superelastic behavior on unloading. In the case of $\hat{\gamma}$, this behavior was also observed in studies of water-quenched material containing only the $\alpha^{\prime \prime}$ phase. These changes were small compared with the discrete lattice parameter changes associated with the first-order phase transformation.

\section{DISCUSSION}

From the lattice correspondences developed by Hatt, ${ }^{21}$ the $\gamma^{0} \rightarrow \alpha "$ transformation would be expected to proceed according to the mechanism depicted in Fig. 11. Shear on the $\{112\}<111>$ (cubic indices) system along with minor atom shuffles would transform the $\gamma^{\circ}$ tetragonal lattice to the monoclinic $\alpha^{\prime \prime}$ lattice. When lattice parameters for the tetragonal 


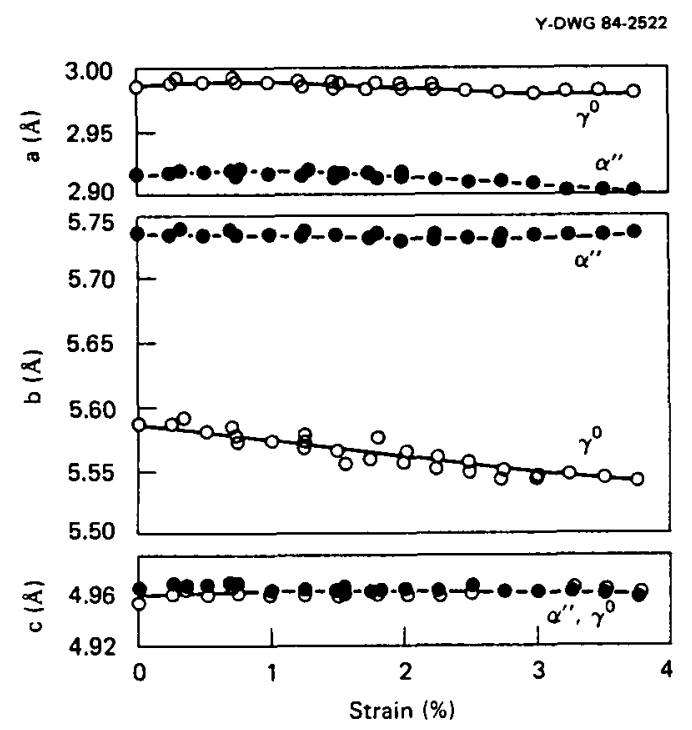

Fig. 8. Variation of monoclinic lattice parameters for the $\alpha^{\prime \prime}$ and $\gamma^{\circ}$ lattices with strain in an aged $\mathrm{U}-6.47 \mathrm{Nb}$ alloy.

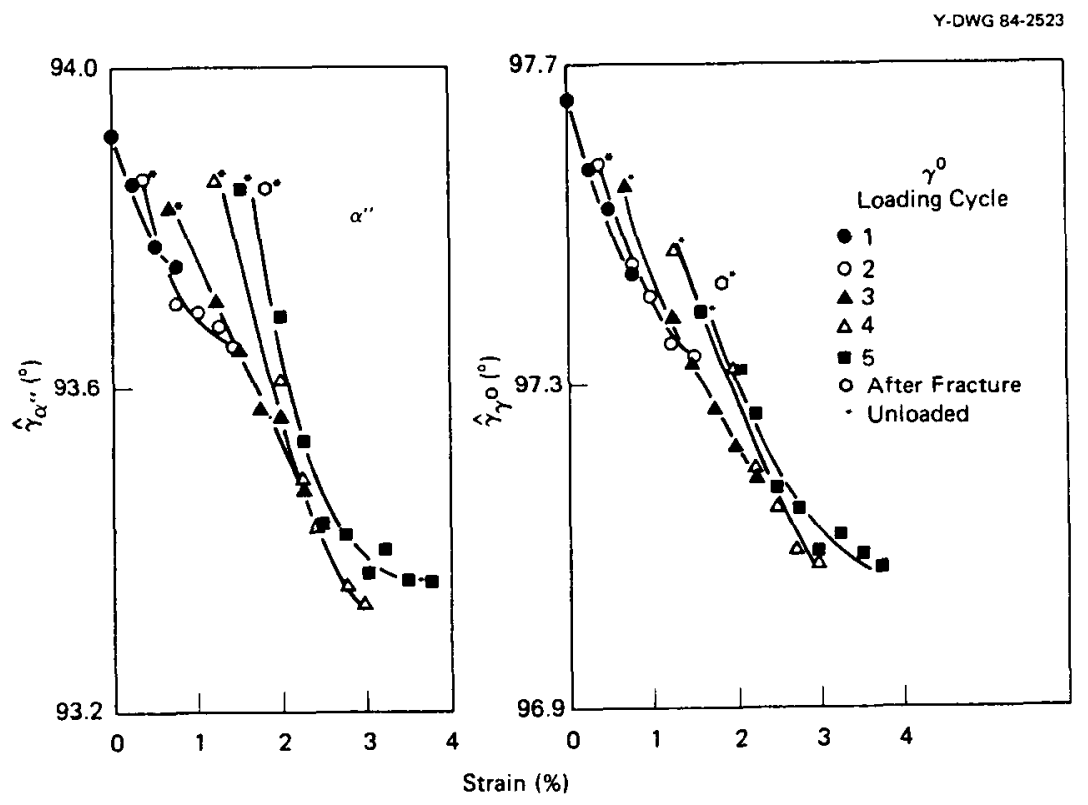

Fig. 9. Variation of the monoclinic angle $(\hat{\gamma})$ of the $\alpha^{\prime \prime}$ and $\gamma^{\circ}$ lattices with strain in a $\mathrm{U}-6.47 \mathrm{Nb}$ alloy. 


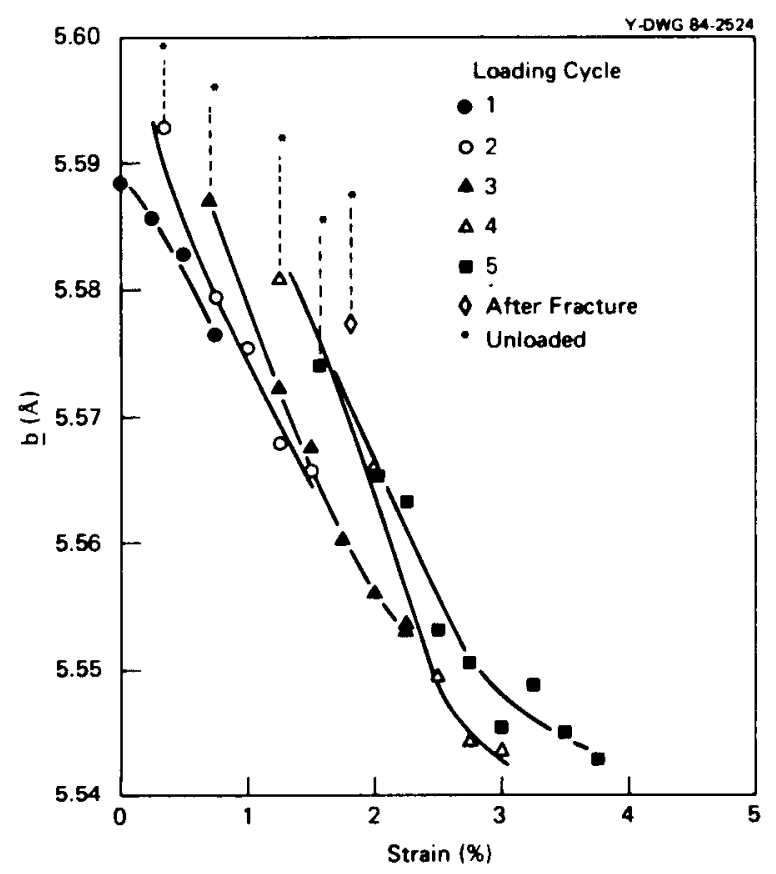

Fig. 10. The b lattice parameter for the yo phase, based upon the corresponding monoclinic $a^{\prime \prime}-1$ ike cell, as a function of strain for an aged $U-6.47 \mathrm{Nb}$ alloy.

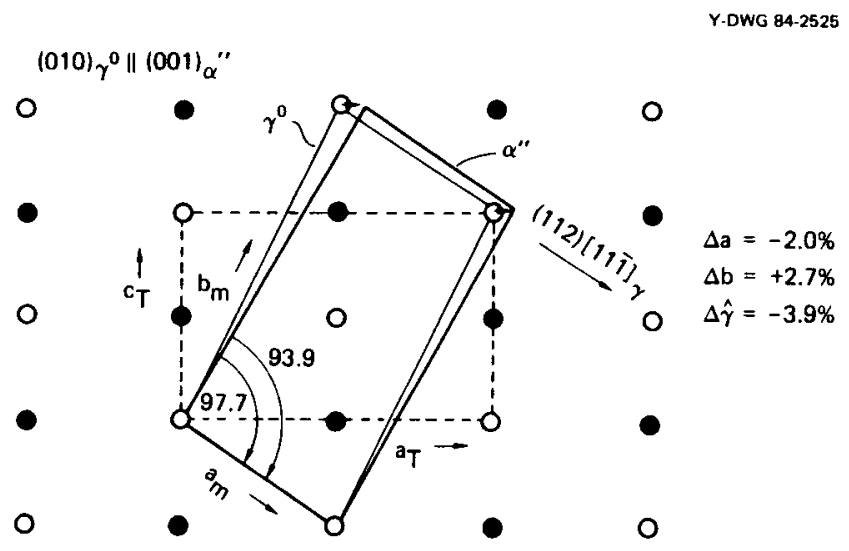

Fig. 11. Mechanism of $\gamma^{0} \rightarrow \alpha^{n}$ phase transformation. (Minor atom shifts in the ro phase are not shown; nor are shuffles required to complete the transformation.) 
unit cell were converted to the corresponding monoclinic cell, it could be seen that the phase transformation was accompanied by a decrease in the a lattice parameter $(-2.0 \%)$, an increase in the $\underline{b}$ parameter $(+2.7 \%)$, no change in the $c$ parameter, and a decrease in the $\hat{\gamma}$ angle $(-3.9 \%)$. The decrease in $\hat{\gamma}$ corresponds to the transformation shear. The overall lattice volume change was positive $(+1.29 \%)$.

These figures were based upon measurements made in the initial undeformed condition. With increasing deformation, both $\Delta a$ and $\Delta b$ increased, giving rise to an increasingly greater volume change. At the largest strain under load, the volume difference was a surprising $6.8 \%$. The lattice dimensional changes occurring at the interphase interfaces accounted for some of the back stress resisting the forward transformation. The increasing volume difference between the $\gamma^{0}$ and $\alpha^{\prime \prime}$ phases would be expected to increase the back stress, suggesting a strainhardening effect. This would add a positive component to the slope of the easy-flow region of the stress-strain curve.

The source of the strength increase of the aged material over that of the water-quenched material should probably be addressed at this point. As was suggested previously, the movements of interphase and intervariant interfaces appear to be energetically similar, indicating that the strength increase was not due to a large transformation backstress. As Vandermeer has pointed out, uranium-niobium alloys with lower niobium compositions undergo strength increases as a result of low-temperature aging, but they do not form the stabilized $\gamma^{0}$ phase. It was suggested that the strength increase in the case of aged $U-5.8 \mathrm{Nb}$ was due to the interaction of moving intervariant interfaces with relatively coherent aging clusters (12). In the case of aged $U-6.5 \mathrm{Nb}$, both intervariant and interphase interfaces could interact with aging clusters to produce the increase in strength.

In containing a significantly smaller amount of $\alpha^{\prime \prime}$ phase, Samples 1 and 2 differ from Sample 3. A visual examination of the diffraction patterns of Samples 1 and 2 indicated that Sample 1 contained somewhat less $\alpha^{\prime \prime}$ phase than Sample 2. These differences are probably not unexpected when the rapid variation in $M_{S}$ near this composition is considered along with the differences in niobium composition among the three samples.

The source of sample superelasticity is not known with certainty, although these data allow some speculation. It was interesting to note that elasticity seemed to be associated with interphase interfaces in Sample 1 and with intervariant $\alpha^{\prime \prime}$ interfaces in Sample 2. If we assumed that all of the interfaces were highly elastic, then the elasticity measured by XRD would depend upon the number of interfaces involved. With either process, after sufficient movement had occurred, the unstable phase or unfavorably oriented variant was consumed and interfaces were destroyed. ${ }^{1}$ Thus, unless new interfaces were created (or old ones recreated) on unloading, the recovery must have been less than that obtained on loading. Apparently interphase interfaces were destroyed on loading and not re-created on unloading at the higher strain values of Sample 2. 
In Sample 1, few interphase interfaces were destroyed on loading to $1.8 \%$ strain so that the elasticity of the remaining interfaces combined to produced a large phase reversion on unloading. Sample 3 showed relatively lower interphase interface elasticity even at lower strains. The reason was that in Sample 3 , with its higher initial $\alpha^{\prime \prime}$ content, more interphase interfaces were destroyed at lower strain values than in Samples 1 and 2. Interestingly, the few interphase interfaces which remained in cycles 4 and 5 were not destroyed to any significant extent, so recovery on unloading was almost complete. One possible reason for the elasticity of the interphase interfaces in the fourth and fifth cycles may have been the larger volume change necessary to complete the transformation at the higher strains. The higher back-stress would increase the elasticity of the remaining interfaces. Additionally, the remaining interphase interfaces may have been unfavorably oriented with respect to the uniaxial force vector so that the resolved shear stress on the $\{112\}<111>_{\gamma}$ shear system was small, and the resulting movement of interfaces was also small.

The data from Samples 2 and 3 indicated that after most of the interphase interfaces had been annihilated, deformation took place primarily by movement of intervariant interfaces. The low elasticity of the interphase interfaces at the higher strains in this study was a surprising result since in other alloy systems in which deformation occurs by a martensitic transformation superelasticity was the result of the retreat of interphase interfaces. Apparently, it was easier in the $\mathrm{U}-6.4 \mathrm{Nb}$ alloy to relieve the springback stresses by twining in the $\alpha^{\prime \prime}$ phase than by nucleating $\gamma^{\circ}$ in those grains where interphase interfaces had been annihilated. This may be related to the fact that in the water-quenched specimens, $\alpha^{\prime \prime}$ was more thermodynamically stable than $\gamma^{\circ}$; perhaps stress reversed the transformation behavior which had been established by aging.

The sources of interface elasticity are not known with certainty at this point. The association with the aging process is strong since the intervariant interfaces were significantly more elastic in the aged condition than in the water-quenched condition. ' Libermann's model of twin interface movement in the gold-cadmium alloy, $\mathrm{Au}-\mathrm{Cd}$, must certainly be considered as a source of elasticity in the case of intervariant interface movement, as suggested previously. ${ }^{1}$ One potential source of some specimen elasticity may be the highly anisotropic responses of the $\alpha^{\prime \prime}$ and ro lattices to stress. The small, continuous changes in lattice parameters were similar to changes observed in both $\alpha^{\prime \prime}$ and $\gamma^{\circ}$ alloys subjected to tensile deformation. 1,20 The changes in the $\alpha^{\prime \prime}-\hat{\gamma}$ angle were much greater here than in the water-quenched $\alpha^{\prime \prime}$ alloy of the same composition $^{1,3}\left(0.6^{\circ}\right.$ in the aged alloy, and $0.2^{\circ}$ in the water-quenched alloy over $0 \%-3 \%$ strain region). This may be related to lattice softening near the martensitic phase transformation. This phenomenon has been associated with a number of martensitic phase transformations. ${ }^{22}$ The atom movements responsible for these continuous lattice parameter changes were small compared with those abrupt changes responsible for interface movement. The resulting springback probably made only a small contribution to the specimen elasticity. However, the anelastic unloading response observed in mechanical stress-strain tests might be related to a difference in the rate of relaxation between the lattice and the interfaces, as suggested in Zener's model of anelasticity. ${ }^{23}$ 


\section{CONCLUSIONS}

In uranium-niobium alloys near the monotectoid composition, the low-temperature aging-induced tetragonal $\gamma^{\circ}$ phase transforms to the monoclinic $\alpha^{\prime \prime}$ phase via a thermoelastic, martensitic phase transformation when deformed near room temperature. The transformation resulted in a lattice volume expansion ranging from $1.29 \%$ in the undeformed state to $6.8 \%$ at $3.75 \%$ strain.

Reversible deformation in the aged $\mathrm{U}-6.5 \mathrm{Nb}$ alloy took place primarily by the movement of partially elastic interphase and intervariant interfaces. The movement of interphase interfaces was a result of the $\gamma^{\circ} \rightarrow \alpha^{\prime \prime}$ thermoelastic martensitic phase transformation while intervariant interface movement was initially associated with the preexisting $\alpha^{\prime \prime}$ phase.

Once interphase interfaces were annihilated under stress, they did not recover to a large extent on unloading. The elasticity exhibited by the specimen was due mainly to the retreat of the remaining interphase interfaces and to the retreat and possible creation of additional intervariant interfaces. At the higher strains attained in this study $(3 \%-4 \%)$, only the intervariant interfaces recovered significantly on unloading. Thereafter, reversible strain accommodation was associated primarily with the movement of intervariant interfaces. The anelastic unloading response may be related to differences in the rate of relaxation between the interfaces and the highly elastic, soft $\alpha^{\prime \prime}$ and $\gamma^{\circ}$ lattices. 


\section{ACKNOWLEDGMENTS}

The author wishes to acknowledge Dr. R. A. Vandermeer for suggesting this experiment and for the many stimulating discussions of martensitic phase transformations and the shape memory effect. Also, the careful attention to detail by A. D. Condrey with the experimental measurements is gratefully appreciated. 


\section{REFERENCES}

1. R. A. Vandermeer, D. A. Carpenter, and A. G. Dobbins, Reversible Strain Mechanisms in Uranium-Niobium Alloys Near the Monotectoid Composition, Y-2285, Union Carbide Corp. Nuclear Div., Oak Ridge Y-12 Plant, October 1983.

2. R. A. Vandermeer et al., "Effects of Tensile Deformation on the Strain Memory Behavior of Uranium-Niobium $\alpha^{\prime \prime}$ Martensite," p. 1229, in Proceeding of an International Conference on Solid-Solid Phase Transformations, 1982, Carnegie-Mellon University, Pittsburgh, Pa.

3. D. A. Carpenter and R. A. Vandermeer, "X-Ray Diffraction Study of Shape Memory in Uranium-Niobium Alloys," p. 307, Advances in $X-R \alpha y$ Analysis, vol 26, Plenum Publishing, 1983.

4. D. A. Carpenter and R. A. Vandermeer, "An X-Ray Diffraction Study of a Martensitic Transformation in Uranium Alloy," Journal de Physique 43, C4-395 (1982).

5. R. J. Jackson, Reversible Martensitic Transformations between Transition Phases of Uranium-Based Niobium Alloys, RFP-1535, Dow Chemical Company, Rocky Flats, December 23, 1970.

6. R. A. Vandermeer, J. C. Ogle, and W. G. Northcutt, Jr., "A Phenomenological Study of the Shape Memory Effect in Polycrystalline Uranium-Niobium Alloys," Met Trans. A 12A, 733 (1981).

7. R. A. Vandermeer, J. C. Ogle, and W. B. Snyder, Jr., "Shape Memory Effects in a Uranium +14 at $\%$ Niobium Alloy," Scripta Met. 12, 243 (1978).

8. K. Shimizu and K. Otsuka, Shape Memory Effects in Alloys, p. 59, Plenum Press, New York, 1975.

9. L. Delaey and J. Thienel, Shape Memory Effects in Alloys, p. 341, Plenum Press, New York, 1975.

10. D. S. Lieberman, "Phases Transformation," p. 1, Am. Soc. for Metals, Metals Park, Ohio, 1970.

11. D. E. Beck et al., unpublished data, Union Carbide Corp. Nuclear Div., Oak Ridge Y-12 Plant, September 1980.

12. R. A. Vandermeer, Personal communication of unpublished data, Union Carbide Corp. Nuclear Div., Oak Ridge Y-12 Plant, August 1983.

13. R. J. Jackson and D. V. Miley, "Tensile Properties of Gamma Quenched and Aged Uranium-Base Niobium Alloys," Trans. ASM, 61, 336 (1968). 
14. R. A. Vandermeer, "Phase Transformations in a Uranium +14 at $\%$ Niobium," Acta Metall., 28, 383 (1980).

15. K. A. Kaiser, J. J. Dunigan, and P. J. Holzhauser, Improved Techniques for Data Acquisition and Analysis on X-Ray Diffraction Equipment, Y-2282, Union Carbide Corp. Nuclear Div., Oak Ridge Y-12 Plant, July 1983.

16. D. W. Marquardt, "An Algorithm for Least-Squares Estimation of Non-Linear Parameters," J. Soc. Ind. Appl. Math, 11, 431 (1963).

17. D. E. Williams, LCR-2, A FORTRAN Lattice Constant Refinement Program, IS-1052, Ames Laboratory, Iowa State University of Science and Technology, 1964.

18. D. A. Carpenter et al., Phase and Texture Analysis of the Alpha-Phase Extruded Uranium-2.4 Weight Percent Niobium Alloy, Y-2239, Union Carbide Corp. Nuclear Div., Oak Ridge Y-12 Plant, December 1981.

19. B. D. Cullity, Elements of X-Ray Diffraction, Addison-Wesley Publishing Co., Reading, Mass., 1956.

20. D. A. Carpenter, Unpublished data on the $\gamma^{0}$ Alloys, Union Carbide Corp. Nuclear Div., Oak Ridge Y-12 Plant, October 1983.

21. B. A. Hatt, "The Orientation Relationship Between the Gamma and Alpha Structures in Uranium-Zirconium Alloys," J. Nucl. Matr. 19, 133 (1966).

22. N. Nakanishi, Shape Memory Effects in Alloys, p. 147 (and references therein) Plenum Press, New York, 1975.

23. C. Zener, Elasticity and Anelasticity of Metals, The University of Chicago Press, Chicago, Ill., 1948. 


\section{DISTRIBUTION}

Department of Energy - Oak Ridge

Foutch, J. L.

Poteat, R. M.

Lawrence Livermore National Laboratories

Bender, C. F.

Clough, R. E./Galles, H. L.

Mara, G. L.

Miller, G. H.

Ragaini, R. C.

Robbins, J. L.

Root, G. S./Sanford, C. B.

Shuler, W. B./Wraith, C. L.

Technical Information Division

Werne, R. W./Grissom, M. L.

Woods, D. H.

Los Alamos National Laboratories

Hoyt, H. C.

\section{Oak Ridge Gaseous Diffusion Plant}

Wilcox, W. J., Jr.

Oak Ridge National Laboratory

Sommerfield, K. W.

Oak Ridge Y-12 Plant

Beck, D. E.

Brady, K. L.

Burditt, R. B.

Carpenter, D. A. (15)

Chapman, L. R.

Chilcoat, T. R.

Dodson, W. H./Googin, J. M.

Green, L. A.

Hunter, A. H., Jr.

Jessen, N. C., Jr.

Johnson, D. H.

Keith, A.

Kite, H. T.

Koger, J. W.

Kollie, T. G.

In addition, this report is distributed in accordance with the Category UC-25, Materials, as given in the Standard Distribution for Unclassified Scientific and Technical Reports, DOE/TIC-4500. 
Ludtka, Gail M.

Ludtka, Gerard M.

Mills, J. M., Jr.

Northcutt, W. G., Jr.

Smyrl, S. L.

Thompson, J. E.

Y-12 Central Files (master copy)

Y-12 Central Files (route copy)

$\mathrm{Y}-12$ Central Files ( $\mathrm{Y}-12 \mathrm{RC})$

Y-12 Central Files (5)

Naval Ordinance Laboratory - Bethesda, Maryland

Vandermeer, R. A.

Paducah Gaseous Diffusion Plant

Walter, C. W.

Rockwell International - Rocky Flats

Jackson, R. J.

Mataya, M.

Sandia National Laboratories - Livermore

Echlmeyer, K. H. Olson, D. M.

Romig, A. D., Jr. 